\title{
Using Animal Models to Study the Role of the Gut-Brain Axis in Autism
}

\author{
Jess Nithianantharajah ${ }^{1}$ - Gayathri K. Balasuriya ${ }^{2}$ • Ashley E. Franks ${ }^{3}$. \\ Elisa L. Hill-Yardin ${ }^{2,4}$
}

Published online: 12 May 2017

(C) The Author(s) 2017. This article is an open access publication

\begin{abstract}
Purpose of Review Individuals with autism spectrum disorders (ASD) commonly also suffer from gastrointestinal (GI) dysfunction; however, few animal model studies have systematically examined both ASD and GI dysfunction. In this review, we highlight studies investigating GI dysfunction and alterations in gut microbiota in animal models of ASD with the aim of determining if routinely used microbiology and enteric neurophysiology assays could expand our understanding of the link between the two.

Recent Findings Gut-brain axis research is expanding, and several ASD models demonstrate GI dysfunction. The integration of well-established assays for detecting GI dysfunction into standard behavioural testing batteries is needed.

Summary Advances in understanding the role of the gutbrain axis in ASD are emerging; however, we outline standard assays for investigating gut-brain axis function in rodents to strengthen future phenotyping studies. Integrating these findings to the field of animal behaviour is one of the next major challenges in autism research.
\end{abstract}

Jess Nithianantharajah and Gayathri K. Balasuriya contributed equally.

This article is part of the Topical Collection on Autism Spectrum

Elisa L. Hill-Yardin

elisa.hill@rmit.edu.au

1 Florey Institute of Neuroscience and Mental Health, The University of Melbourne, 30 Royal Parade, Parkville, VIC 3052, Australia

2 School of Health and Biomedical Sciences, RMIT University, Bundoora, Melbourne, VIC 3083, Australia

3 Department of Physiology, Anatomy and Microbiology, La Trobe University, Plenty Road, Bundoora, Melbourne, VIC 3086, Australia

4 Department of Physiology, The University of Melbourne, Corner of Royal Parade and Grattan St, Parkville, VIC 3010, Australia
Keywords Autism mouse models · Cognition, behavioural assays · Gastrointestinal dysfunction · Microbiome · Comorbidities

\section{Introduction}

Autism spectrum disorder (ASD) is a prevalent neurodevelopmental disorder affecting as many as 1:45 children in the USA [1]. Diagnosis is based on behavioural traits presenting as impaired social communication and repetitive and/or restrictive behaviours [2]. Along with these core diagnostic traits, individuals with ASD experience a range of comorbidities that vary in severity and combination between individuals and negatively impact quality of life. Gastrointestinal (GI) dysfunction is more prevalent in individuals with ASD than in the general population [3], and emerging welldesigned clinical studies have identified differences in the microbes that inhabit the GI tract in individuals with ASD compared to controls [4-7]. In this review, we outline the potential for animal studies of ASD to elucidate biological mechanisms associated with gut-brain axis changes. We will focus on two genetic models (the chromodomain helicase DNA binding protein 8 and serotonin transporter (CHD8 and SERT) mouse models, respectively) and two environmental models (valproate (VPA) and maternal inflammation activation (MIA)) of autism because GI abnormalities including altered microbial populations (dysbiosis), in addition to core ASD-relevant behavioural phenotypes, have begun to be investigated in these models. These studies are notable for quantifying GI dysfunction and reporting microbial dysbiosis. Here, we provide an overview of how animal models provide a powerful preclinical tool for understanding biological causes of ASD in the drive to identify targets for new therapies. 


\section{Results}

\section{Use and Validity of Animal Models in ASD Research}

The number of animal models of ASD has dramatically increased since the generation of the first genetic mouse model of autism in 2007 [8]; currently, more than 30 models have been reported. Animal models of neurodevelopmental disorders (NDD) are an essential research tool - they allow detailed investigation of associated pathology through the use of powerful but invasive techniques on a background of controlled environmental and genetic factors. Although a single animal model cannot fully replicate the entire disorder state observed clinically, it can, however, model the expression of distinct traits or endophenotypes (including comorbidities) [9] to enable an in-depth analysis of pathological mechanisms and provide potential therapy targets for future clinical applications. In this review, we focus on recent studies assaying gut-brain axis changes in rodent models of ASD (Table 1).

In studying underlying biological mechanisms of NDDs, it is important that animal models adhere to criteria regarding face validity (phenotypes demonstrated by the model relevant to patient diagnostic traits, that is, for ASD, impaired social interaction/communication and repetitive and or restrictive interests), construct validity (the method of generation of the model is relevant to pathology, e.g. a genetic mutation identified in individuals with ASD) and predictive validity (rescue of phenotypes by clinically relevant treatments). Numerous standardised behavioural analyses are now well established for rodent models (reviewed in $[20 \bullet \cdot)$ ).

\section{Assays Relevant to Gut-Brain Axis Function}

In addition to the social and communication impairments in ASD, repetitive or restricted behaviours are core to the disorder. Repetitive behaviours or deficits in response control in ASD are thought to be symptoms of dysfunction in executive processing, which impacts other cognitive functions such attention and cognitive flexibility [21, 22].

Modelling some of the complex cognitive and executive processes often assessed in the clinic, novel behavioural tools such as the rodent touch screen cognitive tests have emerged. This technology allows a systematic and comprehensive analysis of the cognitive profile of rodent models of a NDD within a single testing environment $[23,24]$. Moreover, different cognitive domains relevant to the disorder such as mental flexibility, response control and attention can be measured, with strong translational implications $[25,26]$.

The role of the central nervous system (CNS) in behaviour is well studied in animal models of ASD; however, the involvement of microbes and GI function is a new and rapidly emerging area of research. The complex enteric nervous system (ENS) of the GI tract, also known as the 'second brain', contains roughly equivalent numbers of neurons as the spinal cord. Interactions between the CNS and GI tract occur via multiple neural and endocrine pathways. Predominant neural pathways include the peripheral nervous system (e.g. the vagal nerve, sympathetic nervous system and ENS). The microbiota residing in the GI lumen also impact CNS function; however, the precise pathways involved are not well defined. The ENS is required for GI motility and secretion and comprises two neuronal plexuses adjacent to longitudinal and circular muscle layers in close proximity to microbes in the gut lumen (see [27•] for review). There is also significant cross talk between the immune system, the microbiota and the nervous system which impact behaviour. The ENS regulates GI function and is located in close proximity to microbial populations in the lumen of the GI tract. Gut microbes produce metabolites that function as neurotransmitters and have been established to modulate mood and behaviour; however, our

Table 1 Gut-brain axis studies in animal models of ASD

\begin{tabular}{|c|c|c|}
\hline Animal model & GI phenotype & Reference \\
\hline CHD 8 antisense knockdown zebrafish & Reduced enteric neuronal numbers and slow GI transit. & Bernier et al. [10] \\
\hline CHD 8 heterozygous mice & Shorter GI tract and tendency for slower GI transit & Katayama et al. [11] \\
\hline SERT G56A & $\begin{array}{l}\text { Slower motility, slower GI transit, fewer neurons, } \\
\text { reduced villus height and colonic crypt depth, } \\
\text { reduced intestinal permeability }\end{array}$ & Margolis et al. [12••] \\
\hline Poly(I:C)/MIA mice & $\begin{array}{l}\text { Increased intestinal permeability, increased } \\
\text { interleukin-6 (IL-6) in gut, altered microbiota, } \\
\text { increased levels of 4-EPS (4-ethyl phenylsulphate) } \\
\text { in serum, ASD-like behavioural abnormalities in } \\
\text { the offspring }\end{array}$ & $\begin{array}{l}\text { Smith et al [13]; Hsiao et al. [14]; } \\
\text { Choi et al. [15••] }\end{array}$ \\
\hline Prenatal VPA exposure mice & $\begin{array}{l}\text { Increased inflammation in gut, brain, altered } \\
\text { microbiota, ASD-like behavioural abnormalities } \\
\text { in male offspring }\end{array}$ & $\begin{array}{l}\text { de Theije et al. [16]; de Theije et al. } \\
\text { [17]; Lucchina and Depino [18]; } \\
\text { Kazlauskas et al. [19] }\end{array}$ \\
\hline
\end{tabular}

Examples of animal models in which gastrointestinal abnormalities and/or altered microbial populations have recently been identified include genetic models of ASD, environmental models such as maternal inflammation activation (MIA) and exposure to the antiepileptic, valproate (VPA) 
understanding of the precise pathways involved is in the early stages $[28,29]$. For example, recent findings from animal models demonstrate that gut microbes regulate serotonin levels and in turn mood and behaviour via their influence on microglial cells in the CNS $[14,30 \bullet \cdot]$, but the role of the ENS in this process is only beginning to be understood.

Multiple approaches for assaying gut function are routinely used in enteric neuroscience research and can be incorporated into phenotyping studies of ASD animal models. These also have the potential to be combined with microbial and cognitive behavioural assays for a multidisciplinary holistic view across the major components driving interactions. This multidisciplinary approach will be crucial for improving our understanding of the complex systems physiology underlying behavioural impairments in ASD and the development of novel therapies. The gut houses the largest immune system in the body, and the immune and nervous systems are in constant bidirectional communication $[13,15 \bullet, 31-35]$. Gut microbiota interact closely with neuroimmune pathways $[13,31-34$, $27 \bullet \bullet, 28 \bullet \cdot, 29 \bullet \bullet]$ and play an important role in educating the developing immune system $[28,36 \bullet$, 37]. Gut microbial populations are additionally modified by environmental factors such as diet [37-39] and stress [29], and these are areas that are currently actively being researched in ASD models.

Recent advances in sequencing technology and bioinformatic analysis have exponentially increased the understanding of the microbiome in animal models. Initial studies of the microbiome began through culturing of individual, primarily pathogenic, organisms [40]. High-throughput sequencing now allows the cataloguing of entire microbiomes on different hierarchical levels including chromosomal DNA (genomic), transcribed RNA (transcriptomic) and protein production (proteomic) levels. A combination of techniques allows a holistic approach of the microbial community function and how the microbiome itself may have multifaceted interactions within the gut and brain. Microbiome studies must take into account a number of environmental factors (e.g. home cage housing, diet, age of weaning) as well as ensuring that they are designed to allow sufficient statistical power to provide robust outcomes. High-throughput techniques need to be complemented by traditional culturing, where possible, and temporal and spatial analysis of microbes of interest as well as the application of ecological theory to the complex and continuously evolving microbial community.

In this review, we highlight established assays in the fields of enteric neurophysiology [12, 41-45], microbiology [46-48] and rodent cognitive behaviour [20••, 23-26, 49-54] that in combination will expand our knowledge of gut-brain axis function in animal models of ASD (Fig. 1).

\section{Gut-Brain Axis Studies in Rodent Models of ASD}

ASD aetiology is complex and likely to be the due to a combination of genetic and environmental factors in many cases.
Therefore, we review pertinent studies of two genetic and two environmental models of ASD in which GI dysfunction and/ or microbial dysbiosis is present in order to highlight the use of techniques useful for identifying aberrant gut-brain axis function in animal models in this field. Recent findings suggest ASD-associated mutations in two genes; the chromatin remodelling gene, CHD8, and the solute carrier family 6 member 4 gene (Slc6a4) encoding the serotonin transporter (SERT) protein confer GI dysfunction in animal models [10, $11,12 \bullet \cdot$. Similarly, studies using the maternal inflammation activation (MIA) model (e.g. [13, 14, 15••]) and the administration of the antiepileptic, valproate (VPA) [16, 17], show altered microbial populations, behavioural changes and potential therapeutic targets through the analysis of components of the gut-brain axis.

\section{CHD8 Mutations Are Associated with GI Dysfunction}

Mutations in the chromatin-remodelling gene CHD8 increase susceptibility to ASD and result in macrocephaly, facial phenotypes and GI issues in affected individuals [10]. Bernier and colleagues re-sequenced the CHD8 gene in 3730 children with developmental delay or ASD and identified 15 mutations in CHD8 that were considered potentially disruptive [10]. Previously, these authors identified nine de novo mutations in 2446 ASD patients, all impacting normal protein expression [58]. Importantly, recontacting families involved in this study enabled detailed phenotypic data for individuals with CHD8 mutations. Of the 15 children expressing CHD8 mutations, 12 $(80 \%)$ had GI problems. Of these, $60 \%$ reported recurrent and consistent constipation, which was often reported as periods of constipation followed by loose stool or diarrhoea. The rate of constipation in the CHD8 cohort (15 children) was higher when compared to children diagnosed with ASD but negative for the CHD8 mutation [10] suggesting involvement of the CHD8 gene in GI dysfunction.

To determine the effects of mutating CHD8 on GI function, Bernier and colleagues assessed dose-dependent effects of CHD8 mutations using a knockdown approach in zebrafish. They found that $40-60 \%$ of embryos injected with antisense probes (or morpholinos, a molecular tool to inhibit gene expression and prevent protein synthesis) had fewer enteric neurons than controls as identified by fluorescent immunocytochemical labelling with the pan-neuronal marker, Hu. At increasing concentrations of morpholinos, the effect on enteric neuronal number was more severe [10]. On average, the number of enteric neurons in the hindgut was reduced by an astounding 50\% following knockdown and this was exacerbated in a dosedependent manner suggesting a major role of CHD8 in neuronal development within the GI tract. These findings were a catalyst for further phenotypic analysis in mice lacking CHD8 in order to advance the understanding of disease mechanisms. 

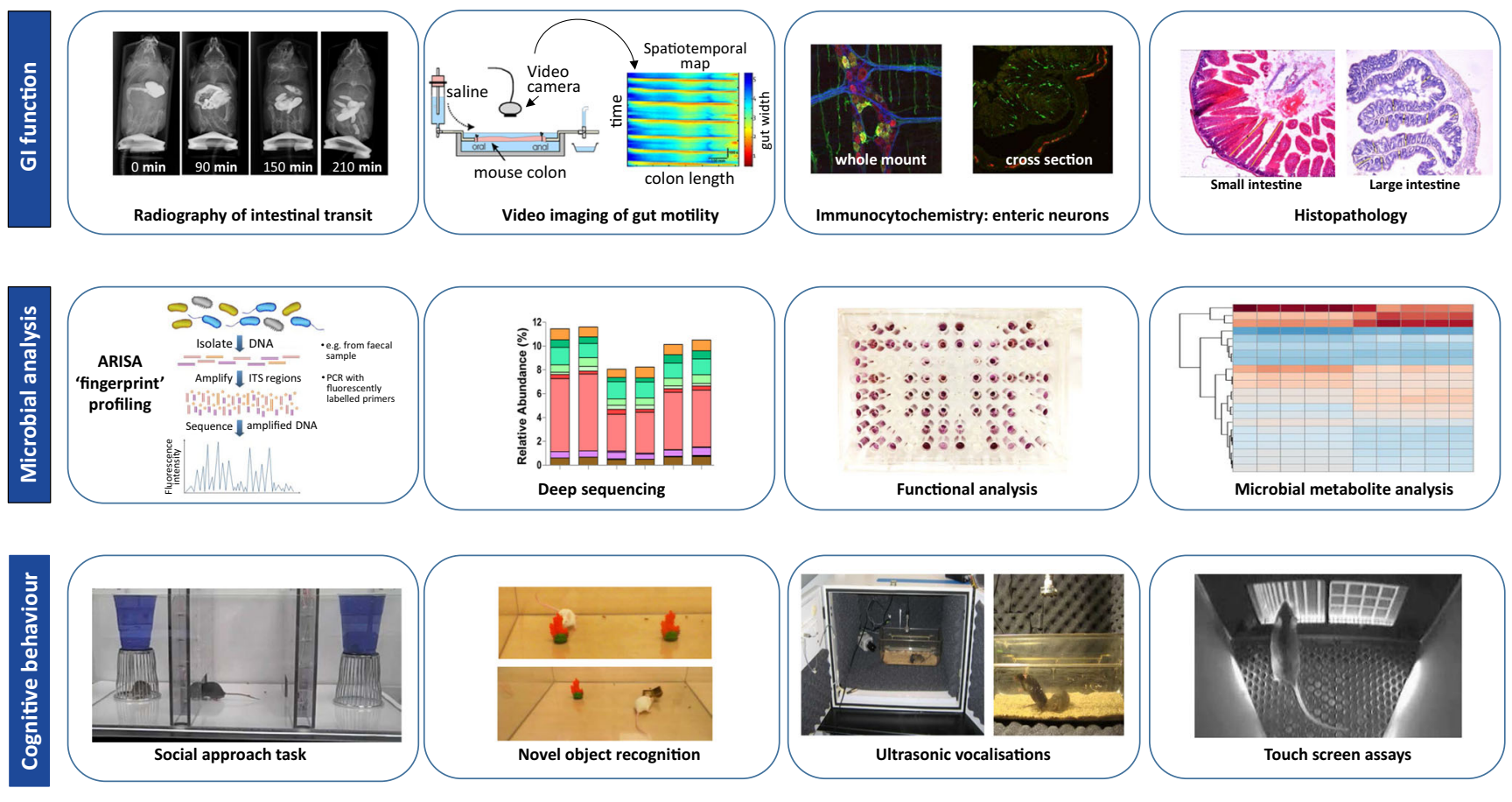

Fig. 1 Assays for investigating gut-brain axis function in rodents. A range of established assays are available for studying gut-brain axis function in rodent models. Functional and structural assays for determining impairments in gastrointestinal function (top) include in vivo serial X-ray imaging to investigate intestinal transit after oral barium sulphate gavage and ex vivo video imaging to quantify changes in GI motility $[42,44]$. Using this method, propagating contractions in a physiological organ bath are video recorded and converted to spatiotemporal maps for detailed analysis [41]. Immunofluorescent labelling of the ENS in whole mount and cross-sectional intestinal preparations and histological labelling for assessing intestinal integrity and morphology (e.g. [45]) can also be undertaken. Structural, functional and predictive approaches to characterise changes in

microbiota are also available (middle). ARISA fingerprints are used to examine the microbial community structure of the intestine, and deep sequencing allows identification of altered abundance in different microbial species. Functional analyses can be carried out by studying Community-Level Physiological Profiles (CLPP) utilising colorimetric assays. Microbial metabolite analysis is carried out by extracting faecal material and analysis through Gas Chromatography-Mass Spectrometry (GC-MS) methods. Cognitive behavioural analyses (bottom) should employ a battery of assays such as the social approach [20••, 49, 52], novel object recognition $[50,54]$ ultrasonic vocalisation assays $[51,55$, $56]$. and touchscreen tests $[25,26,57]$ which provide a robust method to assess cognitive abilities that are clinically relevant

Recently, Katayama and colleagues examined mice heterozygous for mutations in CHD8 [11]. The CHD8 gene produces two isoforms of the CHD8 protein: one the full length and the other containing only the N-terminal domain. Mice homozygous for mutations in either of these CHD8 isoforms are embryonic lethal $[59,60]$. In contrast, $\mathrm{CHD} 8$ heterozygous (het) mice are viable and show increased anxiety, abnormal sensorimotor arousal and gating (as tested by prepulse inhibition paradigms), altered social interaction in some parameters and increased brain weight [11]. CHD8 het mice had neurodevelopmental delay as identified using mouse brain gene set enrichment analysis and suppression of many neuronal genes via the RE-1 silencing transcription (REST) factor. Somewhat surprisingly, learning and memory tests did not show major differences in CHD8 het mice compared with controls. Mutant mice, however, had an increased perseverative phenotype (relevant to ASD behavioural traits) following assessment using the T-maze left-right discrimination test [11]. Katayama and colleagues also reported fewer social contacts and reduced total duration of active contacts (sniffing and

following behaviour). In contrast, another group found that social behaviour in CHD8 het mice was unchanged compared to wild-type littermates [61]. Although environmental differences (potentially involving microbial-behavioural interactions) may contribute to disparate behavioural results in this model, in line with observations of GI dysfunction in those with ASD, Katayama et al. observed that the intestine length in mutant mice was reduced and intestinal transit in 9-weekold mice tended to be slower [11].

Relevant to observations in rodent and zebrafish models, mutations in the CHD8 equivalent homologous gene in drosophila (kismet) result in displaced expression of the hedgehog $(h h)$ gene and alter the development of the central drosophila wing region [62]. Given the strong relevance of CHD8 to ASD relevant behaviour and morphology, the analysis of GI function (and other ASD-relevant phenotypes) in drosophila expressing mutations in kismet could be informative for the mechanistic understanding of GI dysfunction in individuals with ASD.

Further information regarding underlying biological causes of GI impairment in the CHD8 children with ASD could be 
extracted from functional and structural analyses of the GI tract in animal models (e.g. by assessing the number of total enteric neurons and proportions of neuronal subtypes in the myenteric or submucosal plexus). Therefore, the application of neurophysiological GI assays, microbial analyses and clinically relevant cognitive tests to CHD8 mutant models (see Fig. 1) could yield mechanistic findings to improve our understanding of biological mechanisms underpinning GI dysfunction in individuals with ASD.

\section{Altered Serotonin Transporter Activity Impairs GI Function}

Platelet serotonin levels are increased in one third of individuals diagnosed with ASD [63, 64], and serotonin is primarily GI-derived [65]. Platelets take up serotonin [66] as they circulate through the gut via the serotonin transporter, SERT (encoded by the Slc6a4 gene). Many hyperactive mutations in SERT have been reported in individuals with ASD, the most common being SERT Ala56 [67] where a glycine residue is converted to an alanine at position 56 of the protein. This transporter is expressed by enterocytes and serotonergic neurons in the ENS. Serotonin is important in development and adult life and is expressed in a large population of cells located in the GI tract including mucosal enterochromaffin cells, mast cells and a subpopulation of enteric neurons. Serotonin plays an important role in regulating GI motility and secretion, and therefore, changes in serotonergic pathways are highly likely to affect GI function. Serotonin is additionally involved in transmitting signals of noxious stimuli, discomfort and pain to the CNS as well as being a potent modulator of inflammatory pathways $[5,30 \bullet \cdot, 68,69]$.

Margolis et al. conducted a thorough study investigating GI function in mice expressing the SERT Ala56 missense mutation (SERT G56A) using well-established neurophysiological and histological techniques [12••]. In order to understand the role of the SERT transporter in GI function, Margolis and colleagues quantified neuronal numbers in myenteric and submucosal plexuses of the colon and assessed mucosal histology and in vivo transit time as well as ex vivo motility using a well-characterised video-imaging technique [41]. This group studied total neuronal number as well as changes in subpopulations of neurons expressing neurochemical markers such as tyrosine hydroxylase (TH), calcitonin gene-related peptide (CGRP) and gamma-amino butyric acid (GABA). In both the myenteric and submucosal plexuses, neuronal numbers for each of these populations were reduced in SERT G56A mutants. Motility patterns analysed in colonic segments freshly dissected from adult mutant mice showed reduced activity as a result of the SERT G56A mutation. Specifically, the frequency, velocity and contraction length of colonic migrating motility complexes (CMMCs; spontaneous, coordinated contractile activity which propagates from the oral to the anal region of the colon [43]) were reduced in mutant mice.
Following examination of the small intestinal histological structure in these mice, a reduction in villus height and crypt depth in SERT G56A mice was identified. Furthermore, in the colon of SERT G56A mice, crypt depth was reduced and intestinal permeability was increased [12・•]. This study exemplifies the expansion of preclinical knowledge regarding GI dysfunction in ASD mouse models obtained through the use of functional and histological neurophysiology.

\section{Maternal Immune Activation Model of Neurodevelopmental} Disorders

Mice born to dams treated with the immunostimulant polyinosinic/polycytidylic acid (poly I:C) during gestation to mimic viral infection demonstrate impairments in communication, stereotypic behaviours, anxiety and sensorimotor abnormalities relevant to ASD and dysbiosis of faecal microbiota [14]. Similar to the VPA model discussed below, the imbalance of microbes in offspring of MIA-treated mice was mainly driven by changes in Clostridia and Bacteroidia bacterial classes. Changes in Lachnospiraceae and Ruminococcaceae (of the order Clostridiales) reflect similar findings in ASD individuals with increased faecal Clostridium species [70-72]. Serum levels of adhesion proteins (including tight junction proteins TJP1 and 2 and claudin- 8 and claudin15) were also altered in treated pups suggesting changes in GI mucosal permeability. Interestingly, treatment with Bacteroides fragilis both corrected these adhesion protein deficits and improved several ASD-like behaviours in this mouse model.

In addition to the previous studies, other reports have demonstrated that MIA affects foetal brain development and behaviour via changes in cytokine pathways involving IL-6 [13] and interleukin-17a [15••]. These studies, although not focused on functional assays for GI motility, expand our understanding of how microbiota can potentially impact gut-brain axis function in ASD.

\section{Altered Microbiota in Environmental Rodent Models of ASD}

Prenatal exposure to the anticonvulsant valproate (VPA) is a risk factor for ASD. Exposure to VPA in rodent models results in behavioural impairments (for a review, see [9]). Rodents born following gestational exposure to VPA demonstrate a range of behavioural impairments including decreased social behaviours and lower exploratory activity combined with repetitive/stereotypic-like hyperactivity (e.g. see [73]). VPA exposure also causes decreased ultrasonic vocalisation and sociability in mouse pups in addition to elevated digging and grooming behaviours [74]. More recently, reports of dysbiosis, altered GI morphology and CNS inflammation following prenatal VPA treatment in mice have emerged [16-19]. 
Specifically, de Theije and others showed that VPA-treated offspring aged 28 days had decreased abundance of Bacteroidetes phyla mainly consisting of Bacteroidales and increased Firmicutes microbial taxa, mainly consisting of Clostridiales [16]. When caecal concentrations of shortchain fatty acids were measured, these authors observed increased butyric acid in VPA-treated male mice compared to controls (pups born to dams not exposed to VPA). Changes in the abundance of microbes belonging to these bacterial groups have also been reported in individuals with ASD $[5,6,70,75]$ (also see [76••]). The short-chain fatty acids (i.e. acetate, butyrate and propionate) are neuroactive microbial metabolites that cross the blood-brain barrier; therefore, the observed increase in butyric acid in this study may have effects on brain function and behaviour. Of particular relevance to GI dysfunction, male pups (but not females) born to VPA-treated dams also showed epithelial cell loss and neutrophil infiltration in the jejunum and ileum as well as reduced serotonin levels in the GI tract [17]. Although the underlying cause of the sexspecific effects is unknown, a role for VPA in inhibiting testosterone to oestradiol conversion [77] has been proposed which could partly explain this finding.

Recently, the detailed discussion of optimal experimental design in studying environmental effects influencing host-microbe interactions in animal models has emerged [78]. This is important because a low level of reproducibility for behavioural approaches has been identified [79], which slows research progress. Furthermore, issues with reproducibility could be due to subtle methodological differences that alter contributions of microbial populations to behavioural outcomes. The use of these best practice guidelines together with validated assays should enable greater consistency between laboratories when endophenotyping animal models of ASD.

\section{Conclusions}

Alterations in gut-brain axis signalling affect mood and behaviour; however, current understanding of the precise biological signalling pathways involved is incomplete. As summarised in this review, the use of genetic and environmental animal models has begun to contribute to characterising biological mechanisms (including a potential role for dysbiosis) underlying these changes. These studies will be important for not only aiding our understanding of basic mechanisms, but also assisting in identifying future therapeutic targets to improve outcomes for those with ASD. However, in light of the range of techniques outlined here that are routinely available, further exploration of functional and structural GI changes in animal models with detailed histological analysis of ENS morphology and mucosal integrity is required. In addition, emerging data suggest that modulating gut microbes impact behaviour and cognition; therefore, future research in animal models using appropriate behavioural experimental assays is required to gain a more comprehensive understanding of the role of the gut-brain axis in the context of ASD.

Acknowledgements ELH-Y was supported by an ARC Future Fellowship (FT160100126) and a Vice-Chancellor's Senior Research Fellowship at RMIT University. The authors gratefully acknowledge the generous contribution of unpublished images from Dr. K. Nurgali (Barium X-ray transit) and Dr. J.L. Silverman (behavioural assays).

\section{Compliance with Ethical Standards}

Conflict of Interest Dr. Nithianantharajah, Dr. Balasuriya, Dr. Franks, and Dr. Hill-Yardin have no conflict of interest.

Human and Animal Rights and Informed Consent All reported studies/experiments with human or animal subjects performed by the authors have been previously published and complied with all applicable ethical standards (including the Helsinki Declaration and its amendments, institutional/national research committee standards and international/national/institutional guidelines).

Open Access This article is distributed under the terms of the Creative Commons Attribution 4.0 International License (http:// creativecommons.org/licenses/by/4.0/), which permits unrestricted use, distribution, and reproduction in any medium, provided you give appropriate credit to the original author(s) and the source, provide a link to the Creative Commons license, and indicate if changes were made.

\section{References}

Papers of particular interest, published recently, have been highlighted as:

- Of importance

•• Of major importance

1. Zablotsky B, Black LI, Maenner MJ, Schieve LA, Blumberg SJ. Estimated prevalence of autism and other developmental disabilities following questionnaire changes in the 2014 National Health Interview Survey. National health statistics reports. 2015(87):1-20.

2. Association AP. Diagnostic and statistical manual of mental disorders. 5th ed. Arlington: American Psychiatric Publishing; 2013.

3. McElhanon BO, McCracken C, Karpen S, Sharp WG. Gastrointestinal symptoms in autism spectrum disorder: a metaanalysis. Pediatrics. 2014;133(5):872-83. doi:10.1542/peds.20133995.

4. Vuong HE, Hsiao EY. Emerging roles for the gut microbiome in autism spectrum disorder. Biol Psych. 2017;81(5):411-23. doi:10. 1016/j.biopsych.2016.08.024.

5. Luna RA, Savidge TC, Williams KC. The brain-gut-microbiome axis: what role does it play in autism spectrum disorder? Curr Dev Disord Rep. 2016;3(1):75-81. doi:10.1007/s40474-016-0077-7.

6. Kang DW, Adams JB, Gregory AC, Borody T, Chittick L, Fasano A, et al. Microbiota transfer therapy alters gut ecosystem and improves gastrointestinal and autism symptoms: an open-label study. Microbiome. 2017;5(1):10. doi:10.1186/s40168-016-0225-7. 
7. Hsiao EY. Gastrointestinal issues in autism spectrum disorder. Harvard Review of Psychiatry. 2014;22(2):104-11. doi:10.1097/ hrp.0000000000000029.

8. Tabuchi K, Blundell J, Etherton MR, Hammer RE, Liu X, Powell $\mathrm{CM}$, et al. A neuroligin-3 mutation implicated in autism increases inhibitory synaptic transmission in mice. Science. 2007;318(5847): 71-6. doi:10.1126/science.1146221.

9. Argyropoulos A, Gilby KL, Hill-Yardin EL. Studying autism in rodent models: reconciling endophenotypes with comorbidities. Front Human Neurosci. 2013;7:417. doi:10.3389/fnhum.2013. 00417.

10. Bernier R, Golzio C, Xiong B, Stessman HA, Coe BP, Penn O, et al. Disruptive CHD8 mutations define a subtype of autism early in development. Cell. 2014;158(2):263-76. doi:10.1016/j.cell.2014. 06.017 .

11. Katayama Y, Nishiyama M, Shoji H, Ohkawa Y, Kawamura A, Sato T, et al. CHD8 haploinsufficiency results in autistic-like phenotypes in mice. Nature. 2016;537(7622):675-9. doi:10.1038/ nature 19357

12.• Margolis KG, Li Z, Stevanovic K, Saurman V, Israelyan N, Anderson GM, et al. Serotonin transporter variant drives preventable gastrointestinal abnormalities in development and function. $\mathrm{J}$ Clin Invest. 2016;126(6):2221-35. doi:10.1172/jci84877. This highly detailed study utilizes many of the gastrointestinal assays outlined in the current review.

13. Smith SE, Li J, Garbett K, Mirnics K, Patterson PH. Maternal immune activation alters fetal brain development through interleukin-6. J Neurosci. 2007;27(40):10695-702. doi:10.1523/ JNEUROSCI.2178-07.2007.

14. Hsiao EY, McBride SW, Hsien S, Sharon G, Hyde ER, McCue T, et al. Microbiota modulate behavioral and physiological abnormalities associated with neurodevelopmental disorders. Cell. 2013;155(7):1451-63. doi:10.1016/j.cell.2013.11.024.

15.• Choi GB, Yim YS, Wong H, Kim S, Kim H, Kim SV, et al. The maternal interleukin-17a pathway in mice promotes autism-like phenotypes in offspring. Science. 2016;351(6276):933-9. doi:10. 1126/science.aad0314. Elegant study highlighting neuroimmune interactions, specifically disrupted cortical layering due to inflammatory stimuli.

16. de Theije CG, Wopereis H, Ramadan M, van Eijndthoven T, Lambert $\mathrm{J}$, Knol J, et al. Altered gut microbiota and activity in a murine model of autism spectrum disorders. Brain Behav Immun. 2014;37:197-206. doi:10.1016/j.bbi.2013.12.005.

17. de Theije CG, Koelink PJ, Korte-Bouws GA, Lopes da Silva S, Korte SM, Olivier B, et al. Intestinal inflammation in a murine model of autism spectrum disorders. Brain Behav Immun. 2014;37:240-7. doi:10.1016/j.bbi.2013.12.004.

18. Lucchina L, Depino AM. Altered peripheral and central inflammatory responses in a mouse model of autism. Autism Res. 2014;7(2): 273-89. doi:10.1002/aur.1338.

19. Kazlauskas N, Campolongo M, Lucchina L, Zappala C, Depino AM. Postnatal behavioral and inflammatory alterations in female pups prenatally exposed to valproic acid. Psychoneuroendocrinology. 2016;72:11-21. doi:10.1016/j.psyneuen.2016.06.001.

20.• Silverman JL, Yang M, Lord C, Crawley JN. Behavioural phenotyping assays for mouse models of autism. Nat Rev Neurosci. 2010;11(7):490-502. doi:10.1038/nrn2851. Excellent introduction to mouse models of autism and the relevant behavioural assays.

21. Turner M. Annotation: repetitive behaviour in autism: a review of psychological research. J Child Psychol Psychiatry. 1999;40(6): 839-49.

22. Lopez BR, Lincoln AJ, Ozonoff S, Lai Z. Examining the relationship between executive functions and restricted, repetitive symptoms of autistic disorder. J Autism Dev Disord. 2005;35(4):445-60. doi:10.1007/s10803-005-5035-x.
23. Nithianantharajah J, Komiyama NH, McKechanie A, Johnstone M, Blackwood DH, St Clair D, et al. Synaptic scaffold evolution generated components of vertebrate cognitive complexity. Nat Neurosci. 2013;16(1):16-24. doi:10.1038/nn.3276.

24. Bussey TJ, Holmes A, Lyon L, Mar AC, McAllister KA, Nithianantharajah J, et al. New translational assays for preclinical modelling of cognition in schizophrenia: the touchscreen testing method for mice and rats. Neuropharmacology. 2012;62(3):1191203. doi:10.1016/j.neuropharm.2011.04.011.

25. Nithianantharajah J, McKechanie AG, Stewart TJ, Johnstone M, Blackwood DH, St Clair D, et al. Bridging the translational divide: identical cognitive touchscreen testing in mice and humans carrying mutations in a disease-relevant homologous gene. Sci Rep. 2015;5: 14613. doi:10.1038/srep14613.

26. Nithianantharajah J, Grant SG. Cognitive components in mice and humans: combining genetics and touchscreens for medical translation. Neurobiol Learn Mem. 2013;105:13-9. doi:10.1016/j.nlm. 2013.06.006.

27. Furness JB. The enteric nervous system and neurogastroenterology. Nat Rev Gastroenterol Hepatol. 2012;9(5):286-94. doi:10.1038 nrgastro.2012.32. Thorough and accessible review for both experts and interdisciplinary researchers.

28. Ho P, Ross DA. More than a gut feeling: the implications of the gut microbiota in psychiatry. Biol Psych. 2017;81(5):e35-e7. doi:10. 1016/j.biopsych.2016.12.018.

29. Cryan JF, Dinan TG. Mind-altering microorganisms: the impact of the gut microbiota on brain and behaviour. Nat Rev Neurosci. 2012;13(10):701-12. doi:10.1038/nrn3346.

30.• Yano JM, Yu K, Donaldson GP, Shastri GG, Ann P, Ma L, et al. Indigenous bacteria from the gut microbiota regulate host serotonin biosynthesis. Cell. 2015;161(2):264-76. doi:10.1016/j.cell.2015. 02.047. Insightful study identifying the role of spore forming microbes in regulating serotonin levels.

31. Veiga-Fernandes H, Mucida D. Neuro-immune interactions at barrier surfaces. Cell. 2016;165(4):801-11. doi:10.1016/j.cell.2016. 04.041.

32. Mowat AM, Agace WW. Regional specialization within the intestinal immune system. Nat Rev Immunol. 2014;14(10):667-85. doi: $10.1038 /$ nri3738.

33. Mowat AM. Anatomical basis of tolerance and immunity to intestinal antigens. Nat Rev Immunol. 2003;3(4):331-41. doi:10.1038/ nri1057.

34. Gabanyi I, Muller PA, Feighery L, Oliveira TY, Costa-Pinto FA, Mucida D. Neuro-immune interactions drive tissue programming in intestinal macrophages. Cell. 2016;164(3):378-91. doi:10.1016/j. cell.2015.12.023. Important insights into neuro-immune function in the gastrointestinal tract.

35. Bienenstock J, Kunze W, Forsythe P. Microbiota and the gut-brain axis. Nutr Rev. 2015;73(Suppl 1):28-31. doi:10.1093/nutrit/nuv019.

36. Fung TC, Olson CA, Hsiao EY. Interactions between the microbiota, immune and nervous systems in health and disease. Nat Neurosci. 2017;20(2):145-55. doi:10.1038/nn.4476. Recent overview of evidence for the role of the gut-brain axis in disease, including relevance to ASD.

37. Cox LM, Blaser MJ. Antibiotics in early life and obesity. Nat Rev Endocrin. 2015;11(3):182-90. doi:10.1038/nrendo.2014.210.

38. Scott KP, Gratz SW, Sheridan PO, Flint HJ, Duncan SH. The influence of diet on the gut microbiota. Pharmacol Res. 2013;69(1):5260. doi:10.1016/j.phrs.2012.10.020.

39. Kashyap PC, Marcobal A, Ursell LK, Larauche M, Duboc H, Earle $\mathrm{KA}$, et al. Complex interactions among diet, gastrointestinal transit, and gut microbiota in humanized mice. Gastroenterology. 2013;144(5):967-77. doi:10.1053/j.gastro.2013.01.047.

40. Schloss PD, Handelsman J. Status of the microbial census. Microbiology and molecular biology reviews : MMBR. 2004;68(4):686-91. doi:10.1128/MMBR.68.4.686-691.2004. 
41. Swaminathan M, Hill-Yardin E, Ellis M, Zygorodimos M, Johnston LA, Gwynne RM, et al. Video imaging and spatiotemporal maps to analyze gastrointestinal motility in mice. Journal of visualized experiments : JoVE. 2016;108:53828. doi:10.3791/53828.

42. Robinson AM, Rahman AA, Carbone SE, Randall-Demllo S, Filippone R, Bornstein JC, et al. Alterations of colonic function in the Winnie mouse model of spontaneous chronic colitis. Am J Physiol Gastrointest Liver Physiol. 2017;312(1):G85-g102. doi: 10.1152/ajpgi.00210.2016.

43. Roberts RR, Murphy JF, Young HM, Bornstein JC. Development of colonic motility in the neonatal mouse-studies using spatiotemporal maps. Am J Physiol Gastrointest Liver Physiol. 2007;292(3): G930-8. doi:10.1152/ajpgi.00444.2006.

44. McQuade RM, Stojanovska V, Donald E, Abalo R, Bornstein JC, Nurgali K. Gastrointestinal dysfunction and enteric neurotoxicity following treatment with anticancer chemotherapeutic agent 5-fluorouracil. Neurogastroenterol Motil. 2016;28(12):1861-75. doi:10. 1111/nmo.12890.

45. Balasuriya GK, Hill-Yardin EL, Gershon MD, Bornstein JC. A sexually dimorphic effect of cholera toxin: rapid changes in colonic motility mediated via a 5-HT3 receptor-dependent pathway in female C57Bl/6 mice. J Physiol. 2016;594(15):4325-38. doi:10. 1113/jp272071.

46. Wang B, Liu W, Liu X, Franks AE, Teng Y, Luo Y. Comparative analysis of microbial communities during enrichment and isolation of DDT-degrading bacteria by culture-dependent and-independent methods. Sci Total Environ. 2017;590:297-303. doi:10.1016/j. scitotenv.2017.03.004.

47. Summers ZM, Fogarty HE, Leang C, Franks AE, Malvankar NS, Lovley DR. Direct exchange of electrons within aggregates of an evolved syntrophic coculture of anaerobic bacteria. Science. 2010;330(6009):1413-5.

48. Butterly CR, Phillips LA, Wiltshire JL, Franks AE, Armstrong RD, Chen $\mathrm{D}$, et al. Long-term effects of elevated $\mathrm{CO} 2$ on carbon and nitrogen functional capacity of microbial communities in three contrasting soils. Soil Biol Biochem. 2016;97:157-67.

49. Yang M, Silverman JL, Crawley JN. Automated three-chambered social approach task for mice. Curr Protoc Neurosci. 2011; doi:10. 1002/0471142301.ns0826s56. Chapter 8:Unit 8.26

50. Yang M, Lewis FC, Sarvi MS, Foley GM, Crawley JN. 16p11.2 deletion mice display cognitive deficits in touchscreen learning and novelty recognition tasks. Learning \& memory (Cold Spring Harbor, NY). 2015;22(12):622-32. doi:10.1101/lm.039602.115.

51. Wohr M, Silverman JL, Scattoni ML, Turner SM, Harris MJ, Saxena R, et al. Developmental delays and reduced pup ultrasonic vocalizations but normal sociability in mice lacking the postsynaptic cell adhesion protein neuroligin2. Behav Brain Res. 2013;251: 50-64. doi:10.1016/j.bbr.2012.07.024.

52. Silverman JL, Pride M, Hayes J, Puhger K, Butler-Struben H, Baker $\mathrm{S}$, et al. GABAB receptor agonist $\mathrm{R}$-baclofen reverses social deficits and reduces repetitive behavior in two mouse models of autism. Neuropsychopharmacology. 2015;40(9):2228-39.

53. Silverman JL, Gastrell PT, Karras MN, Solomon M, Crawley JN. Cognitive abilities on transitive inference using a novel touchscreen technology for mice. Cereb Cortex. 2015;25(5):1133-42. doi:10. 1093/cercor/bht293

54. Flannery BM, Silverman JL, Bruun DA, Puhger KR, McCoy MR, Hammock BD, et al. Behavioral assessment of NIH Swiss mice acutely intoxicated with tetramethylenedisulfotetramine. Neurotoxicol Teratol. 2015;47:36-45.

55. Torquet N, de Chaumont F, Faure P, Bourgeron T, Ey E. mouseTube - a database to collaboratively unravel mouse ultrasonic communication. F1000Research. 2016;5:2332. doi:10.12688/ f1000research.9439.1.

56. Ey E, Torquet N, Le Sourd AM, Leblond CS, Boeckers TM, Faure $\mathrm{P}$, et al. The autism ProSAP1/Shank2 mouse model displays quantitative and structural abnormalities in ultrasonic vocalisations. Behav Brain Res. 2013;256:677-89. doi:10.1016/j.bbr.2013.08. 031.

57. Copping NA, Berg EL, Foley GM, Schaffler MD, Onaga BL, Buscher N, et al. Touchscreen learning deficits and normal social approach behavior in the Shank3B model of Phelan-McDermid syndrome and autism. Neuroscience. 2017;345:155-65. doi:10. 1016/j.neuroscience.2016.05.016.

58. O’Roak BJ, Vives L, Girirajan S, Karakoc E, Krumm N, Coe BP, et al. Sporadic autism exomes reveal a highly interconnected protein network of de novo mutations. Nature. 2012;485(7397):24650. doi:10.1038/nature10989.

59. Nishiyama M, Oshikawa K, Tsukada $\mathrm{Y}$, Nakagawa T, Iemura $\mathrm{S}$, Natsume T, et al. CHD8 suppresses p53-mediated apoptosis through histone $\mathrm{H} 1$ recruitment during early embryogenesis. Nat Cell Biol. 2009;11(2):172-82. doi:10.1038/ncb1831.

60. Nishiyama M, Nakayama K, Tsunematsu R, Tsukiyama T, Kikuchi A, Nakayama KI. Early embryonic death in mice lacking the betacatenin-binding protein Duplin. Mol Cell Biol. 2004;24(19):838694. doi:10.1128/mcb.24.19.8386-8394.2004.

61. Wright J. Mouse with key autism mutation defies expectations. Spectrum News. 2016. https://spectrumnews.org/news/mousewith-key-autism-mutation-defies-expectations/. Accessed 1 Feb 20172017.

62. Terriente-Felix A, Molnar C, Gomez-Skarmeta JL, de Celis JF. A conserved function of the chromatin ATPase Kismet in the regulation of hedgehog expression. Dev Biol. 2011;350(2):382-92. doi: 10.1016/j.ydbio.2010.12.003.

63. Ritvo ER, Yuwiler A, Geller E, Ornitz EM, Saeger K, Plotkin S Increased blood serotonin and platelets in early infantile autism. Arch Gen Psychiatry. 1970;23(6):566-72.

64. Mulder EJ, Anderson GM, Kema IP, de Bildt A, van Lang ND, den Boer JA, et al. Platelet serotonin levels in pervasive developmental disorders and mental retardation: diagnostic group differences, within-group distribution, and behavioral correlates. J Am Acad Child Adolesc Psychiatry. 2004;43(4):491-9. doi:10.1097/ 00004583-200404000-00016.

65. Gershon MD. Review article: roles played by 5-hydroxytryptamine in the physiology of the bowel. Aliment Pharmacol Ther. 1999;13(Suppl 2):15-30.

66. Hughes FB, Brodie BB. The mechanism of serotonin and catecholamine uptake by platelets. J Pharm Exp Ther. 1959;127:96-102.

67. Sutcliffe JS, Delahanty RJ, Prasad HC, McCauley JL, Han Q, Jiang $\mathrm{L}$, et al. Allelic heterogeneity at the serotonin transporter locus (SLC6A4) confers susceptibility to autism and rigid-compulsive behaviors. Am J Hum Genet. 2005;77(2):265-79. doi:10.1086/ 432648.

68. Mawe GM, Hoffman JM. Serotonin signalling in the gut-functions, dysfunctions and therapeutic targets. Nat Rev Gastro Hep. 2013;10(8):473-86. doi:10.1038/nrgastro.2013.105.

69. Lomax AE, O'Hara JR, Hyland NP, Mawe GM, Sharkey KA. Persistent alterations to enteric neural signaling in the guinea pig colon following the resolution of colitis. Am J Physiol Gastrointest Liver Physiology. 2007;292(2):G482-91. doi:10.1152/ajpgi. 00355.2006

70. Luna RA, Oezguen N, Balderas M, Venkatachalam A, Runge JK, Versalovic J, et al. Distinct microbiome-neuroimmune signatures correlate with functional abdominal pain in children with autism spectrum disorder. Cell Mol Gastroenterol Hepatol. 2017;3(2): 218-30. doi:10.1016/j.jemgh.2016.11.008.

71. Finegold SM, Molitoris D, Song Y, Liu C, Vaisanen ML, Bolte E, et al. Gastrointestinal microflora studies in late-onset autism. Clin Infect Dis. 2002;35(Suppl 1):S6-s16. doi:10.1086/341914.

72. De Angelis M, Piccolo M, Vannini L, Siragusa S, De Giacomo A, Serrazzanetti DI, et al. Fecal microbiota and metabolome of children with autism and pervasive developmental disorder not 
otherwise specified. PLoS One. 2013;8(10):e76993. doi:10.1371/ journal.pone.0076993.

73. Schneider T, Przewlocki R. Behavioral alterations in rats prenatally exposed to valproic acid: animal model of autism. Neuropsy chopharmacology. 2005;30(1):80-9. doi:10.1038/sj.npp.1300518.

74. Moldrich RX, Leanage G, She D, Dolan-Evans E, Nelson M, Reza $\mathrm{N}$, et al. Inhibition of histone deacetylase in utero causes sociability deficits in postnatal mice. Behav Brain Res. 2013;257:253-64. doi: 10.1016/j.bbr.2013.09.049.

75. Kang DW, Park JG, Ilhan ZE, Wallstrom G, Labaer J, Adams JB, et al. Reduced incidence of Prevotella and other fermenters in intestinal microflora of autistic children. PLoS One. 2013;8(7): e68322. doi:10.1371/journal.pone.0068322.

76.• Tightening the case for gut microbiota in autism-spectrum disorder. Cell Mol Gastroenterol Hepatol. 2017;3(2):Braun J, 131-2. doi:10. 1016/j.jcmgh.2017.01.010. Insightful overview of current standing of the field in terms of emerging microbial signatures. That ASD may occur in gestation is highlighted as problematic ethically for addressing these issues in humans whereas mouse models of ASD are useful. The choice of mucosal biopsy to obtain a sample that is likely to be physiologically stable is important.

77. Tauboll E, Gregoraszczuk EL, Kolodziej A, Kajta M, Ropstad E. Valproate inhibits the conversion of testosterone to estradiol and acts as an apoptotic agent in growing porcine ovarian follicular cells. Epilepsia. 2003;44(8):1014-21.

78. Stappenbeck TS, Virgin HW. Accounting for reciprocal hostmicrobiome interactions in experimental science. Nature. 2016;534(7606):191-9. doi:10.1038/nature18285.

79. Troublesome variability in mouse studies. Nat Neurosci. 2009;12(9):1075. doi:10.1038/nn0909-1075. 